\title{
Public Private Partnership'- Public Private Partnership: The New Panacea in Oral Health
}

\author{
Vikram Pal Aggarwal* \\ Department of Public Health Dentistry, Surendera Dental College and Research Institute, India
}

Submission: July 14, 2017 ; Published: April 04, 2018

*Corresponding author: Vikram Pal Aggarwal, Department of Public Health Dentistry, Surendera Dental College and Research Institute, India, Tel: 07734879313; Email: drvikramaggarwal@yahoo.com

\section{Abstract}

Deficiencies in the public sector health system in providing health services to the population are well documented. The inability of the public health sector has forced poor and deprived sections of the population to seek health services from the private sector. Evidence indicates that, in many parts of India, the private sector provides a large volume of health services but with little or no regulation. The private sector is not only India's most unregulated sector but also it is the most potent and unexploited sector. To address the inefficiency and inequity in the health system, many state governments have undertaken health sector reforms. One of these reforms has been to collaborate with the private sector through Public/Private Partnership (PPP). State governments in India are experimenting partnerships with the private sector to reach the poor and underserved sections of the population. Thus this review focuses on the importance of public private partnership in oral health.

Keywords: Health care; Oral health; Public-private partnership

\section{Introduction}

In spite of great achievements in oral health globally, problems still remain in many countries all over the world, particularly among developing countries. In India, though health care is provided individually through public and private sectors, till now the oral health has not reached its summit. One of the strategies to improve oral health is through encouraging Public-Private Partnership (PPP) [1]. Although widely used, the term partnership is difficult to define. Some definitions [2] in the literature are so ambiguous that they cover practically any type of interaction between public and private actors. Yet partnership is often used to describe a range of inter-organizational relationships and collaborations. The useful definitions of public-private partnership are:

a) Means to bring together a set of actors for the common goal of improving the health of a population based on the mutually agreed roles and principles [3].

b) A partnership means that both parties have agreed to work together in implementing a program, and that each party has a clear role and say in how that implementation happens [4].

c) A form of agreement that entails reciprocal obligations and mutual accountability, voluntary or contractual relationships, the sharing of investment and reputational risks, and joint responsibility for design and execution [5].

The need to foster such arrangements is supported by a clear understanding of the public sectors inability to provide public goods entirely on their own, in an efficient, effective and equitable manner because of lack of resources and management issues [6]. The aggregate expenditure on health sector is $5.2 \%$ of the GDP; out of this, $17 \%$ is for public sector and $83 \%$ for private sector. But in case of oral health it is $0 \%$, hence it is vital to promote publicprivate partnership (PPP) for preventive, curative, and promoted services in stirring the oral health. These partnerships blend political, economic, and social forces to raise awareness of the oral health needs of undeserved population and to provide inspiration for a public consciousness. Their combined effort produces an impact that is greater than the sum of the individual parts [7].

\section{The evolution of PPP}

PPP emerged as a result of five contextual shifts:

a) An ideological shift in the 1990s from "freeing" the market (i.e., liberating business from restrictive bureaucracy) to "modifying" the market (i.e., creating a facilitating environment).

b) A growing disillusionment with the UN and its agencies and their overlapping mandates, parallel programs, and interagency competition.

c) An increasing recognition that the health agenda is so large that no single sector or organization can tackle it alone [8].

d) A realization that the market alone cannot solve the problems. Public involvement is needed if health services, drugs, and vaccines are to reach the poor [9]. 
e) A growing interest among private players to enhance their involvement in social issues and to be seen as ethically and socially responsible. For example, Unilever's mission statement declares that "corporate social responsibility is an integral part of our operating tradition" [10].

\section{Strategies}

There are a number of strategies that can enhance the success of partnerships. These include employing the principles of good governance, the selection of appropriate partners, transparency, accountability and good communications, fair competition, equity, and the evaluation of externalities.

\section{Ethical challenges}

These are largely generic across the range of public-private partnerships relate to the dimensions such as global norms and principals, impartiality in health, social safety nets, conflict of interest, redirecting national health polices, contribution to common goals and objectives, lack of outcome orientation6.

\section{Contributions/role of private/ public sector in PPP}

a) Planning, designing, and development of health care facilities in whole or specialty wise.

b) Owning and operating diagnostic services for public health systems.

c) Owning and operating other services like mobile clinics.

d) Provision of tax incentives to encourage private sector investment in health care capacity, building, education, and training.

e) Allowing corporate entities to venture into health care education will generate private sector interest and have an immediate impact on increasing the training capacity [1].

\section{Dental health care: public versus private sector}

\section{Public sector:}

a) Government rural hospitals provide minimal dental treatment. b) Government civil and district hospitals, as well as Primary Health Care Centre provide very basic dental treatment. Limited centres are available across the country.

c) Apart from defluoridation of drinking water, fluoride supplements, and some anti-tobacco awareness activities, no other primary dental health care preventive measures are undertaken.

\section{Private sector:}

a) Dental institutes offer treatment at reduced cost, but hospital-based and individual dental practices are costly.

b) Dental associations, some pharmaceutical companies, institutes, and NGOs are promoting oral health awareness.

c) Almost no cost of outpatient dental treatment is covered under any insurance policy. Recently, few policies have been launched, but their true potential of coverage is indeterminable.

\section{Potential private sector partners and their tasks in improving oral health}

a) Pharmaceutical companies: These companies should produce relatively low-cost toothpaste, mouthwashes, provision of non-cariogenic medicine.

b) Media: It has an immense potential of having a mass long term impact on public, with banners and holdings regarding the hazards of smoking and tobacco.

c) Financing companies: Can help by providing discount vouchers, subsidies and duty exemptions.

d) Professional associations: Can help by making the regular rural services compulsory.

e) General practitioners: Should adopt policy of referring every patient to dental health clinic for oral health promotion and prevention.

f) Paramedical staff: Staff working under PHC, CHC, and rural health centres (village guides, dais, anganwadi workers), can be trained by the private practitioner to provide preventive aids.

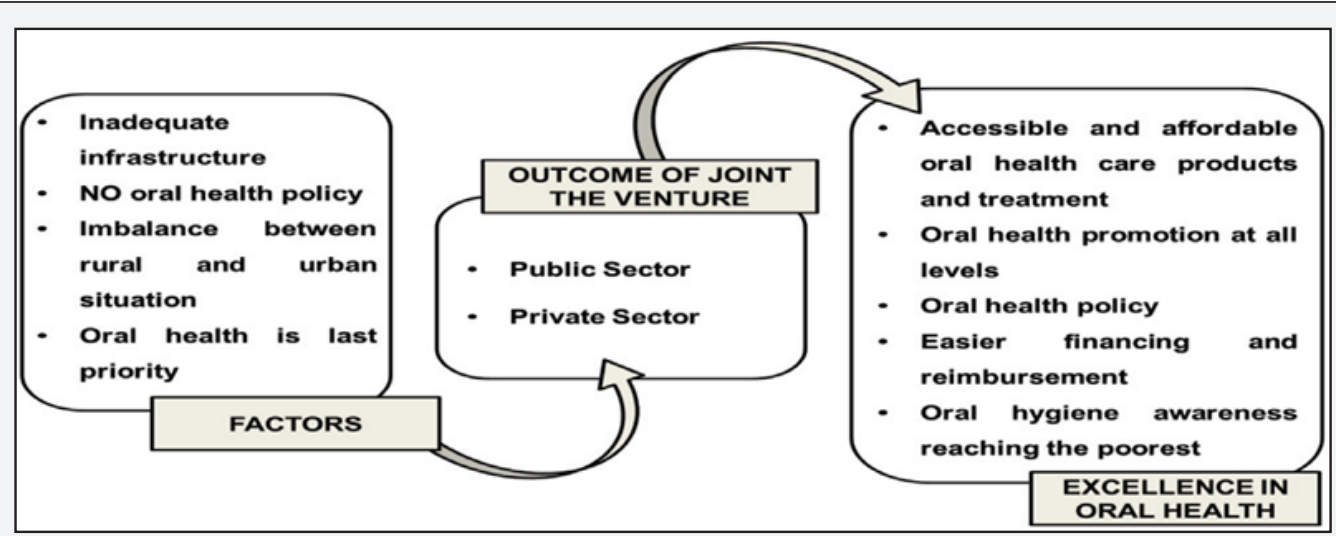

Figure 1: Role of PPP and its impact. 


\section{Advances in Dentistry \& Oral Health}

\section{Potential role of PPP}

PPP brings convergence of private sector interests and public sector goals. It intends to optimally utilize and enable increased access to vast rural, poor and marginalized segments like slum dwellers, etc. Government contributions to a PPP should not be under looked because without its support, planning oral health excellence will be like building a castle in the air. It plays a major role in providing infrastructure (creating a post for dentist in every PHC) and provide capital subsidy in the form of a one-time grant. Government can develop fiscal policies and increase taxation on harmful products like tobacco, alcohol, and cariogenic products, and exempt taxation on healthy products like sugar substitutes, fruits and vegetables, herbal products, dentifrice, and mouthwash. In the current scenario, the impact of joint venture of public and private sector is schematically presented in Figure 1 [1].

\section{Public Private Partnership in India}

TII: The Tobacco Intervention Initiative (TII) is a professionallyled "call to action" programme to eradicate tobacco addiction while striving for a 'tobacco free India' and thus improving the oral health of Indians by the year 2020. Tobacco use and smoking in particular, causes many of the chronic and debilitating diseases that affect the population and stress the national health-care system. TII strives for a "Tobacco Free India" by helping patients quit smoking and consumption of smokeless or chewing tobacco, through certified dental clinics engaged in tobacco intervention. These clinics form the supportive infrastructure of the initiative for tobacco cessation [11].

Yeshasvini health scheme in Karnataka: The Yeshasvini Co-operative Farmer's Healthcare Scheme is a health insurance scheme targeted to benefit the poor. It was initiated by Narayana Hrudayalaya, super-specialty heart hospital in Bangalore, and by the Department of Co-operatives of the Government of Karnataka. The Government provides a quarter (Rs. 2.50) of the monthly premium paid by the members of the Cooperative Societies, which is Rs.10 per month. The incentive of getting treatment in a private hospital with the Government paying half of the premium attracts more members to the scheme. The cardholders could access free treatment in 160 hospitals located in all districts of the state for any medical procedure costing up to Rs. 2 lakhs. A Third Party Administrator - Family Health Plan Limited that is licensed by Karnataka's Insurance Regulatory and Development Authority. The FHPL has the responsibility for administering and managing the scheme on a day-to-day basis [12].

Arogya Raksha scheme in Andhra Pradesh: The Government of Andhra Pradesh has initiated the Arogya Raksha Scheme in collaboration with the New India Assurance Company and with private clinics. It is an insurance scheme fully funded by the government. It provides hospitalization benefits and personal accident benefits to citizens below the poverty line who undergo sterilization for family planning from government health institutions. The government paid an insurance premium of Rs. 75 per family to the insurance company, with the expected enrolment of 200,000 acceptors in the first year. The medical officer in the clinics issues an Arogya Raksha Certificate to the person who undergoes sterilization. The person and two of her/his children below the age of five years are covered under the hospitalization benefit and personal accident benefit schemes [12].

Contracting in Sawai Man Singh hospital, Jaipur: The SMS hospital has established a Life Line Fluid Drug Store to contract out low cost high quality medicine and surgical items on a 24-hour basis inside the hospital. The agency to operate the drug store is selected through bidding. The successful bidder is a proprietary agency, and the medical superintendent is the overall supervisor in charge of monitoring the store and it's functioning. The contractor appoints and manages the remuneration of the staff from the sales receipts. The SMS hospital shares resources with the drug store such as electricity; water; computers for daily operations; physical space; stationery and medicines. The contractor provides all staff salaries; daily operations and distribution of medicine; maintenance of records and monthly reports to SMS Hospital. The SMS Hospital has also contracted out the installation, operation and maintenance of CT-scan and MRI services to a private agency. The agency is paid a monthly rent by the hospital and the agency has to render free services to $20 \%$ of the patients belonging to the poor socio-economic categories [12].

National rural health mission: has made an impressive beginning to enhance Public Private Partnership. During the eleventh five year plan based on past experiences, efforts have to be made to develop a generic framework for different categories of PPP at primary, secondary, and tertiary levels of oral health care to reduce cost, enhance quality and coverage through extensive stake holder consultations [13].

Mumbai smiles: Mumbai Smiles spreads awareness about oral health, hygiene and improve access to oral health care for the common-man. Driving the importance of oral health, 'Mumbai Smiles' is an initiative in partnership with Wrigley's Orbit, which offers free dental check-ups and educate families on the need to go for regular dental check-ups to ensure a good overall health. Mumbai Smiles not only generates awareness but further reiterates IDA's commitment towards oral health. IDA also made Mumbai proud by breaking the Guinness World Record by conducting the largest number of dental check-ups in 24 hours [14].

Brush up challenge: Brush Up Challenge campaign was started to adopt good oral care habits as many Indians are not aware of the right technique to brush. Some people use finger instead of a brush, black tooth powder, tobacco preparations, herbal twigs, etc. IDA and Colgate-Palmolive (India) Ltd undertook various innovative activities to promote oral healthcare. In October 2007, a record number of 177,003 people brushed their teeth simultaneously at 380 locations across India, in one day, at one time. Thereby successfully creating a Guinness World Record in India for 'most people brushing their teeth (multiple venues)'.

Live Learn. Laugh. Programme: Live. Learn. Laugh. Programme was unveiled in 2006, as a drive for behavioural change and inculcates good oral habits and night brushing in 
children. Low-income families received oral health education on importance of 'tooth-brushing day and night'. Free dental screenings was carried out as many do not have access to dentist on a regular basis. The project is supported by the Federation Dentaire Internationale (FDI), Unilever's Pepsodent brand and IDA [14].

Bright smile and bright future: IDA under the "BRIGHT SMILE AND BRIGHT FUTURE" initiative launched a training programme for Anganwadi workers. Anganwadi - institutions provide basic education to children from lowest rung of the society, in rural areas. Educating these kids on oral health reaps dual results. Kids get the relevant oral health information and in turn educate their parents. Anganwadi workers are trained by a dentist deputed by IDA, to inculcate essential oral care habits in children. This education programme is supported by ColgatePalmolive (India) Limited [15].

\section{Conclusion}

Oral health problems are a perennial global problem, which means a mouthful of silver for the patients and a pocketful of gold for the dentists. This wrongly conceived notion may be one of the reasons why people tend to put dental health on the backburner. To change this notion, PPP, if introduced, can play a magnanimous catalytic role in achieving excellence in oral health. In India IDA has been involved in various school dental health and tobacco cessation programmes but it happens to be symbolic and transitory in nature with minimum impact. Mechanism of accreditation of dental clinics, franchising, and regulation of cost and adoption of standard treatment protocols besides continuum dental education can be way forward to achieve meaningful PPP and attainment of oral health goals.

\section{References}

1. Chavan S, Kemparaj U, Baghele NO, Rajdha A (2012) Public-Private Partnership to Enhance Oral Health in India. Journal of Interdisciplinary Dentistry 2(2): 135-137.

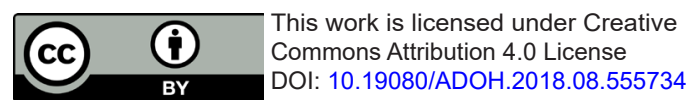

2. http://www.Pppinharyana.Gov.In/Ppp/Sector/Healthreport. Healthcare.Pdf. Last accessed on 29 March 2014.

3. World Health Organization (1999) WHO Guidelines on Collaborations and Partnership with Commercial Enterprise. WHO, Geneva, Switzerland.

4. Blagescu M, Young J (2005) Partnerships and Accountability: Current Thinking and Approaches among Agencies Supporting Civil Society Organizations. Working Paper 255, Overseas Development Institute, England.

5. World Economic Forum (2005) Building on the Monterrey Consensus: The Growing Role of Public-Private Partnerships in Mobilising Resources for Development. United Nations high-level plenary meeting on financing for development, Europe.

6. Nishtar S (2004) Public-private 'partnerships' in health - a global call to action. BioMed Central 2(5): 1-7.

7. http://Www.Astdd.Org. Last accessed on 4 April 2014.

8. Buse K, Walt G (2000) Global Public-Private Partnerships: Part I: A New Development for Health? Bulletin of the WHO 78(4): 549-561.

9. Widdus R (2001) Public-Private Partnerships for Health: Their Main Targets, Their Diversity and Their Future Directions. Bulletin of the WHO 79(8): 713-720.

10. http:// www.globalhandwashing.org. Last accessed on 10 august 2014.

11. http://tii.org.in/AboutTII/aboutti.aspx. Last accessed on 7 April 2014.

12. http://www.ibef.org/download/PublicPrivatePartnership.pdf. Last accessed on 12 April 2014.

13. Sehgal P, Lal S (2011) Enhancing Public Private Partnership in Oral Health Care. Journal of the Indian Association of Public Health Dentistry 18(2): 923-924.

14. http://child.nohp.org.in/About_us1/NOHP.aspx. Last accessed on 14 April 2014.

15. http://nohp.org.in/IDA community/bright smiles bright future. Last accessed on 15 April 2014. 